\title{
APPLICATION OF SOFT COMPUTING METHODS AND SPECTRAL REFLECTANCE DATA FOR WHEAT GROWTH MONITORING
}
V.R.Sharabiani ${ }^{*}$
F. H. Kassar ${ }^{2}$
Y.A.Gilandeh ${ }^{1}$
S. F. Ardabili ${ }^{1}$
Assist. Prof.
Lecturer
Prof
Researcher

1. Dept. Biosystem Engin, Faculty Agric.and Nat.Reso., University of Mohaghegh Ardabili, Ardabil, Iran.

2. Dept. Field Crops, Coll. Agric., University of AL- Muthanna, Samawah, Iraq.

\section{ABSTRACT}

Email: vrasooli@uma.ac.ir

Technology of precision agriculture has caused to the remote sensors development that compute Normalized Difference Vegetation Index (NDVI) parameters. Vegetation indices obtained from remote sensing data can help to summarize climate conditions. Artificial Neural Networks (ANNs), as a soft computing methods, are one of the most efficient methods for computing as compared to the statistical and analytical techniques for spectral data. This study was employed experimental radial basis function (RBF) of ANN models and adaptive neural-fuzzy inference system (ANFIS) to design the network in order to predict the soil plant analysis development (SPAD), protein content and grain yield of wheat plant based on spectral reflectance value and to compare two models. Results indicated that the obtained results of RBF method with high average correlation coefficient $(0.984,0.981$ and 0.9807 in 2015 for SPAD, yield and protein, respectively and $0.979,0.9805$ and 0.984 in 2016) and low RMSE (0.271, 103.315 and 0.111 in 2015 for SPAD, yield and protein, respectively and 0.407, 105.482 and 0.121 in 2016) has the high accuracy and high performance compared to ANFIS models.

Keywords: remote sensing; spectral data analysis; ANFIS; artificial neural networks

شربياني وآخرون

مجلة العلوم الزراعية العراقية -1076-1064:50:2019) مب(4)

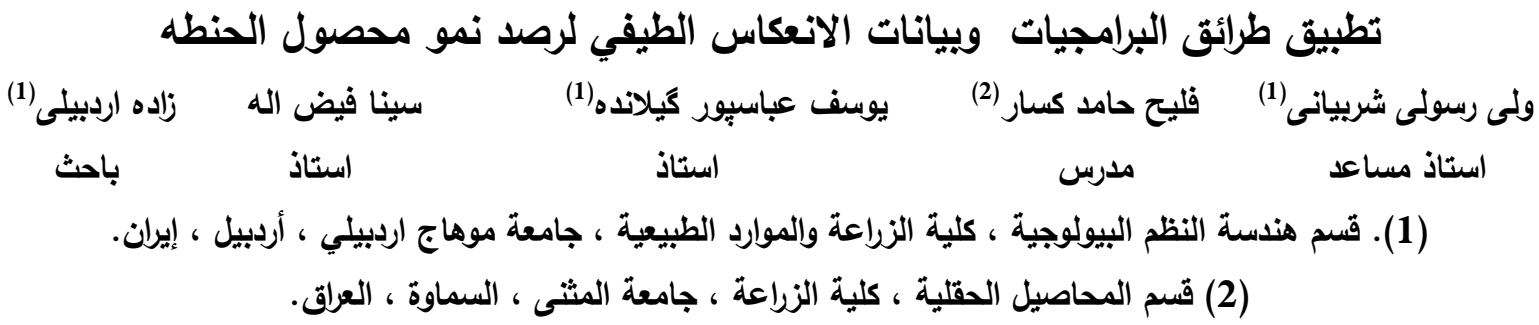

المستخلص

يمكن (NDVI). تقتية الزراعة الدقيقة قد تسببت في تظوير أجهزة الاستثعار عن بُعد التي تحسب صفات مؤثثر اختلاف الغطاء النباتي أن تساعد مؤثرات الغطاء النباتي التي يتم الحصول عليها من بيانات الاستثعار عن بُعد في تلخيص الظروف المناخية. تعد الثبكات العصبية (ANNs) ، مثل طرائق البرامجيات ا، واحدة من أكثر الطرائق الفعالة للحوسبة مقارنةً بالتقتيات الإحصائية والتحليلية للبيانات

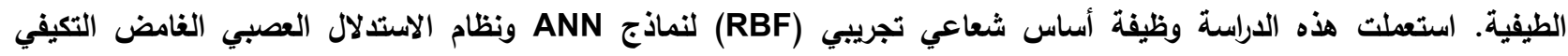
(ANFIS) تصميم الثبكة من أجل التتبؤ بتطوير تحليل نبات الترية (SPAD) ، ومحتوى البروتين وإنتاجية محصول الحنطه على قيمة فئل الانعكاس الطيفي ولمقارنة نموذجين. أثشارت النتائج التي تم الحصول عليها من طريقة RBF بوجود معامل الارتباط عالي (0.984 ، 0.981 و 0.9807 ) لسنة 2015 و (0.979 ، 0.9805 و 0.984 لسنة 2016) لكل من SPAD والحاصل والبروتين على التوالي. وإنخفاض لجذرمتوسط مريع الخطا 0.271 و 103.315 و 0.111 لسنة 2015 كنلك 0.407 ، 105.482

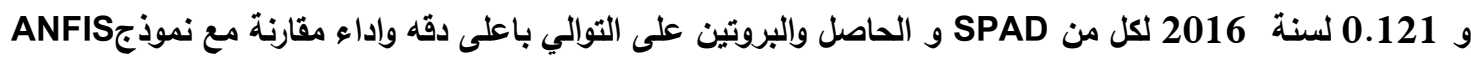
الكلمات المفتاحيه: الاستشعار عن بعد؛ تحليل البيانات الطيفية ؛ ANFIS الشبكات العصبيه 


\section{INTRODUCTION}

The crops monitoring can be performed for ground survey at a local scale. But remote sensing can be appropriated for both in terms of spatial and temporal coverage at the regional scale $(19,24,29)$. Recent development in the field of precision agriculture technology had caused the improvement of crop canopy sensors (groundbased active remote sensors). One of the important topics in the section of remote sensing is classification. The advantages of application of remote sensing techniques are: 1) The lower cost and the covering of large areas (2) The easier classifications $(21,24)$. The remote sensors be able to calculate NDVI, and vegetation indices can find climate conditions $(14,19,26)$. The plant characteristics can be measured indirectly and frequently by waveband (Red wavelengths (R) and Near Infrared (NIR)) (31).

Chemical composition, status of physiological and biomass plant were detected using spectral reflectance (22). Card et al. (2) accurately predicted the amount of nitrogen $(\mathrm{N})$ of ground and dried tree leaves using a spectrometer. They used the Stepwise Multiple Linear Regression (SMLR) and suggested the wave length of $480 \mathrm{~nm}$ and $580 \mathrm{~nm}$ for prediction of nitrogen value $\left(\mathrm{R}^{2}=0.90\right)$. Hansen et al. (11) used multi-way Partial Least Squares regression (N-PLSR) to calculate the protein and yield value of grain. It was indicated that reflectance amount can be able to predict the protein content (11). Researchers can be able to predict the $\mathrm{N}$ value of corn ear leaves using SPAD (chlorophyll meter) at the wavelength of 659 and $940 \mathrm{~nm}\left(\mathrm{R}^{2}=0.962\right)$ (17). They advanced the prediction models using MLR, PLSR and principal component regression (PCR). The results showed that PLSR and PCR were the best models. While, Rasooli Sharabian et al. (27) used the multivariate analysis including of PLSR and SMLR to select the best wavelengths for growth characteristics of winter wheat. The results showed strong relationships between predicted and actual crop variables. They suggested the SMLR as the best model, because it had the highest $R^{2}$ value $(0.85,0.89$ and 0.84 for SPAD, grain protein and yield, respectively) (16,27). Tumbo et al. (30) applied the model of back-propagation neural network for prediction of corn nitrogen. 201 of spectral bands were used as input of the developed model (at range of 407-940 nm). They reported, the neural network model could correlate the amount of chlorophyll well $\left(\mathrm{R}^{2}=\right.$ 0.91) (30).

Development of an alternative technique for determination of crop growth status is an urgent proceeding. Mathematical models had been applied to find the best relationships between data of inputs and outputs. ANNs is a efficient techniques as compared to analytical methods (20). Neural network are able to predict and approximate any nonlinear function (6). ANNs do not require any awareness of fitting function. Therefore, this is one of the main advantage of ANNs. Also, ANNs is very popular due to its ability in estimating and less consuming of time in complex systems modelling compared to another mathematical models such as regression method (9). The ANNs can be used for modelling due to complication of agricultural systems.

The main aim of this study was deployment of experimental Radial Basis Function (RBF) of ANNs models in comparison to adaptive neural-fuzzy inference (ANFIS) system to design a network in order to predict the SPAD, protein content and grain yield of wheat plant based on spectral reflectance value. This work contains 3 steps: 1) processing the requirement data, 2) developing the prediction methods and 3) suggesting and comparing the obtained results.

\section{MATERIAL AND METHODS \\ Data processing}

The reflectance spectral data was obtained with four growth stages (GS36, GS37, GS45 and GS60) of wheat (triticum aestivum L) in each year on two different date $(2015,2016)$ using a portable spectral diameter (Analytical Spectral Devices, Inc., USA). The value of SPAD and canopy reflectance was measured in 2015 at the stage of flag leaf (GS 37) and anthesis (GS 60) in 56 target points as well as in the 2016 (40 target points) after the elongation of stem (GS 36) and anthesis stage (GS 60) growth investigations. The value of 
protein and yield of grain were evaluated after threshing and harvesting at area of $1 \mathrm{~m} \times 3 \mathrm{~m}$ in each target point both two years. The value of SPAD was measured the chlorophyll concentration amount in leaves of plant with determining the leaf absorbance at two regions of red wavelength $(650 \mathrm{~nm})$ and NIR $(940 \mathrm{~nm})$ by a SPAD instrument (MINOLTA Co. LTD.). As shown in SPAD 502 catalogue (24) there is a strong relationship $\left(\mathrm{R}^{2}>0.9\right)$ between nitrogen concentration of leaf and SPAD value .Also, SPAD value has been applied to estimate the nitrogen contents, crop chlorophyll, health status of plant (35). In this research, the value of SPAD had been used as an index for prediction of content of actual nitrogen in leave of crops. Wheat canopy reflectance determines in the $350-2500 \mathrm{~nm}$ wavebands ( $1 \mathrm{~nm}$ interval) were made under cloudless positions and as near to solar noon (27). The first 50 wavelengths (from $350 \mathrm{~nm}$ to $400 \mathrm{~nm}$ ) at the lower visible and last the 1150 readings (from $1350 \mathrm{~nm}$ to $2500 \mathrm{~nm}$ ) at the shortwave infrared (SWIR) were omitted because of their low signal to amount of noise; so, the revised spectra started from $400 \mathrm{~nm}$ (Figure 1).The reflectance on wavelength range of 400-1350 was considered as independent variable and SPAD, Yield and Protein were considered as dependent variables. According to Figure1, Generally, the reflectance of 2016 in green and red visible (VIS) and middle infrared waveband (MIR) was higher, while this reflectance in infrared (NIR) region was lower than reflectance of 2015 on average.

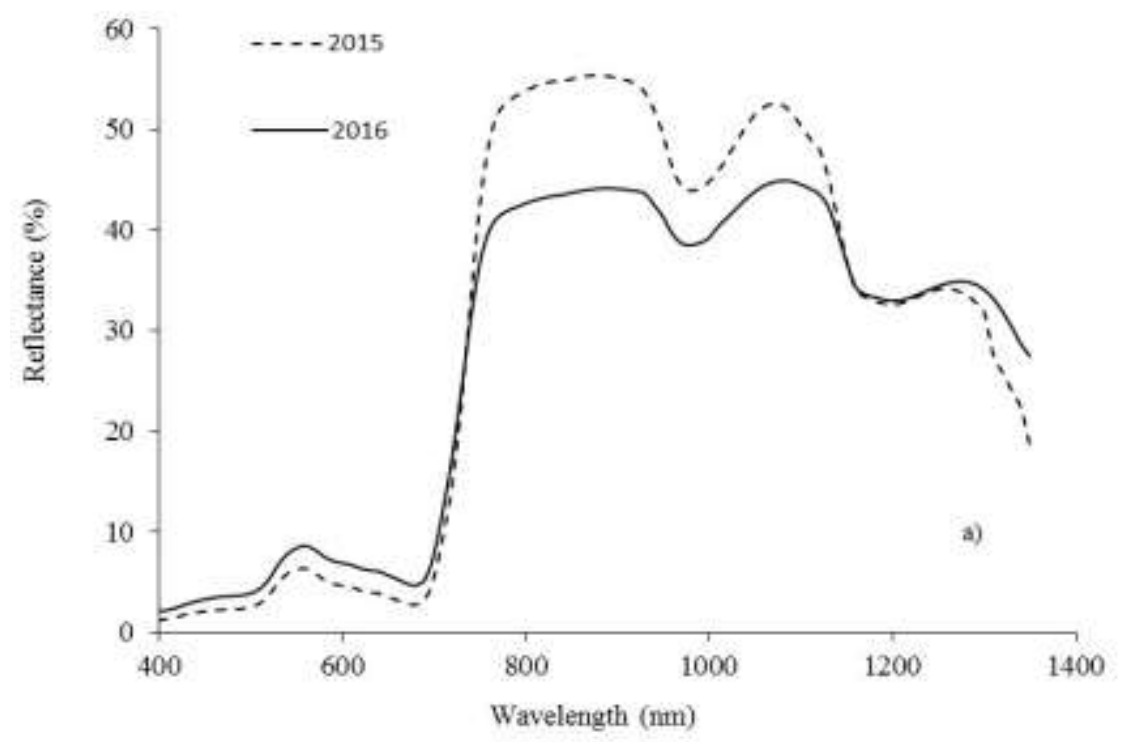

Figure 1. Average of reflectance spectrum of the different experimental treatments for years $(n=56+40)$.

\section{RBF Modelling}

ANNs is used to simulate the system performance, when simulation is needed and restricted experimental data value is available. ANNs includes a large number of neurons or processing elements connected using synaptic weights. In this research, RBF network study is used. $\mathrm{RBF}$ is a learning feed forward network and local type which responds just to a restricted portion of input space. In a hidden layer of RBF network, hidden node maps measure the distances between input to outputs vectors by means of a radial function or nonlinear kernel (33). RBF networks were suggested by other researchers to increase training procedures, and to produce precise approximations with simpler network architecture and an alternative population of RBF networks is then compared to the other neural networks (7). RBF neural networks are used for nonlinear function approximation, data classification, systems modelling, and control (15). They have feed-forward architecture composed of an input layer, a hidden layer with a non-linear RBF function, and a linear output layer. One of the most important characteristic of RBF networks is the hidden layer neurons in the centre of the basis function that produce only local reactions for the input function. This is the reason that 
the basic function can produce a significant nonzero response although the input space falls only in a local area. In other words, the basic functions output may be small (32). The RBF network structure is presented in Figure2.

$$
\begin{array}{lcc}
\text { Input } & \text { Hidden } & \text { Output } \\
\text { Layer } & \text { Layer } & \text { Layer }
\end{array}
$$

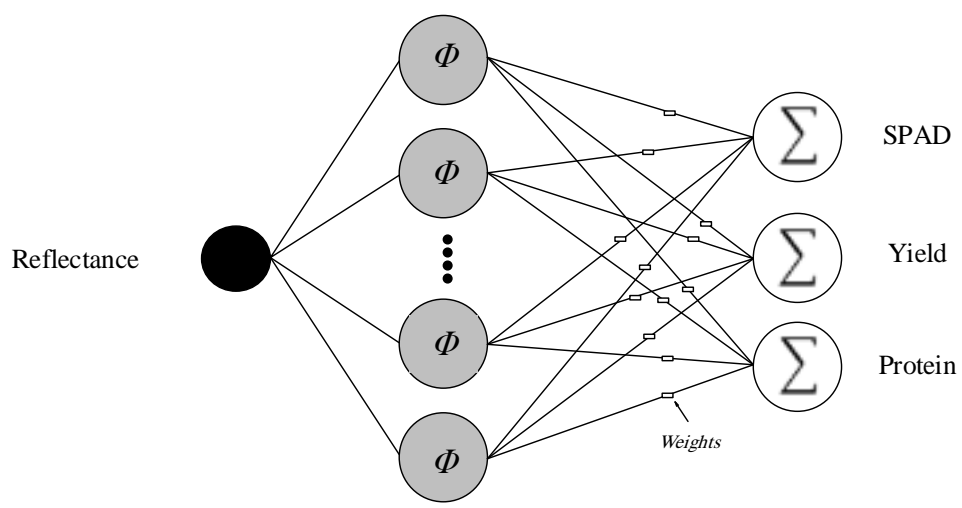

Figure 2. RBF neural network structure.

The output of network is:

$$
y_{k}=\sum_{j=1}^{M} w_{k j} \phi_{j}(x)+w_{k 0}
$$

Where $\mathrm{M}$ : the number of basic functions, $\mathrm{x}$ : the input data vector , $\mathrm{w}_{\mathrm{kj}}$ : weighted connection between the basic function and output layer, and $\varphi_{\mathrm{j}}$ : the nonlinear function of the $\mathrm{j}^{\text {th }}$ unit, which is typically a Gaussian function:

$\phi_{j}(x)=\exp \left(-\frac{\left\|x-\mu_{j}\right\|^{2}}{2 \sigma_{j}^{2}}\right)$

where $\mathrm{x}$ and $\mu$ are the input and the centre unit of RBF, respectively, and $\sigma_{j}$ is the spread of the Gaussian basis function ().

A least mean square (LMS) algorithm had been applied to optimize the weights once of the RBF centres units have been specified. There were two ways to choose the centres: randomly or by clustering algorithms. In this research, centres were selected randomly from a data set.

Percentages of reflectance of each wavelength were the inputs of network and SPAD, Yield and Protein were the outputs of network. In order to train network, after defining the inputs and outputs to the network, there was a need to define the optimum neurons of in the hidden layer. For this purpose, 5 numbers of neurons defined as an initial number of neurons. After running the network with 5 neurons, 5 neurons added to primary neurons and training process was repeated. It was observed that during the network training process with increase of neuron numbers on hidden layer, the error of network decreases, based on performance plot of network. After each repetition 5 neurons were added to the previous neurons number. This action continued until the error reduction was converted into a horizontal line. This number of neurons selected as the optimum neurons on hidden layer.

\section{ANFIS Modelling}

ANFIS is a hybrid of ANN and fuzzy inference system (FIS) that was introduced to overcome the disadvantages of ANN and FIS (9). The ANFIS structure consists of five layers. The ANFIS model was considered with two inputs and one output (Figure 3). 


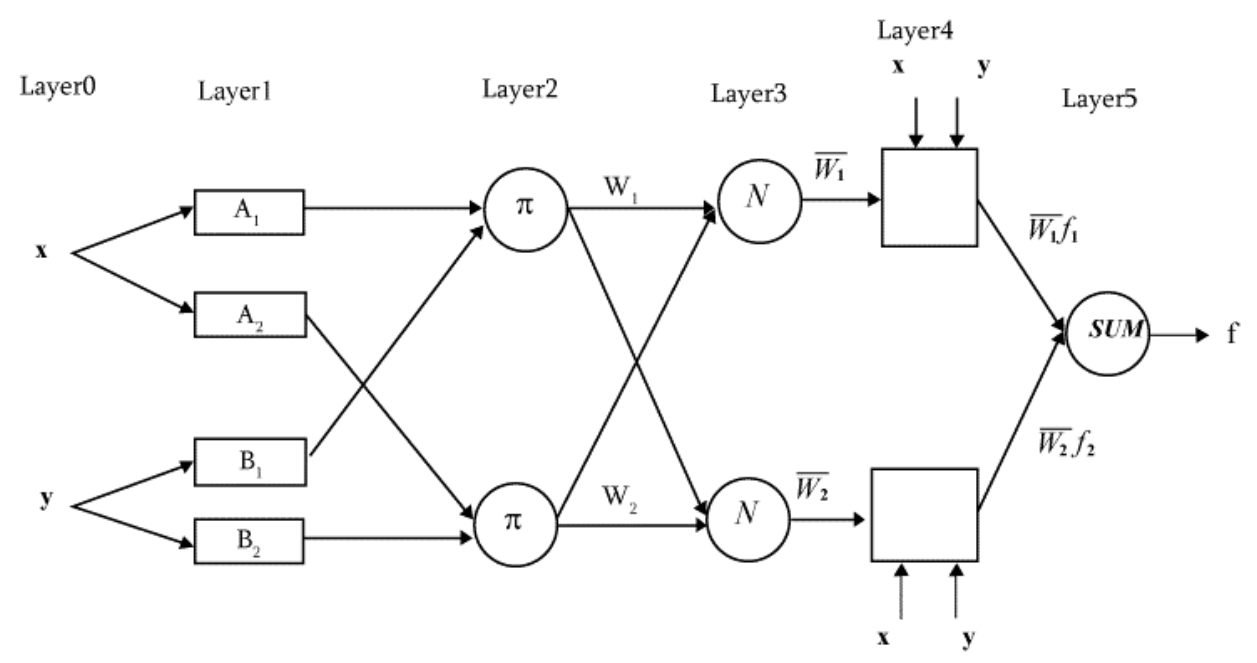

Figure 3. ANFIS structure.

For a first order Sugeno fuzzy model, two fuzzy if-then rules are consumed:

Rule 1: If $x$ is $A_{1}$ and $y$ is $B_{1}$; then $f_{1}=p_{1} x+$ $\mathrm{q}_{1} \mathrm{y}+\mathrm{r}_{1}$

Rule 2: If $x$ is $A_{2}$ and $y$ is $B_{2}$; then $f_{2}=p_{2} x+$ $\mathrm{q}_{2} \mathrm{y}+\mathrm{r}_{2}$

where $A_{1}, A_{2}$ and $B_{1}, B_{2}$ are the fuzzy sets for inputs $x$ and $y$,respectively, $\mathrm{p}_{1}, \mathrm{q}_{1}, \mathrm{r}_{1}$ and $\mathrm{p}_{2}$, $\mathrm{q}_{2}, \mathrm{r}_{2}$ are the parameters of the output function that are specified during the training of ANFIS $(12,23,28)$.

The parameters in the first layer (input layer) are called premise parameters. The rules second layer generates and holds the fuzzy roles. Every node in this layer is a fixed node labelled $\pi$, whose output is the product of all the incoming signals. Every node in third layer is a fixed node labelled $\mathrm{N}$. The $\mathrm{i}^{\text {th }}$ node calculates the ratio of the $i^{\text {th }}$ rules' firing strength. The output of this layer can be called normalized firing strengths. Every node $\mathrm{i}$ in forth layer is an adaptive node. Parameters in this layer are referred to as consequent parameters .And the last layer (Layer 5) calculates the overall output as the summation of all incoming signals $(1,3,9,20)$.

In this study, in order to test and train the ANFIS network, modelling was conducted by ANFIS toolbox in MATLAB R2012a. Also, Sugeno-type fuzzy inference systems had been applied for modelling process. In order to categorize the input data and make the rules, grid partition method is utilized, because of a few input variables. Two various types of input member functions (MFs) consist the trapezoidal (Trap MF) and Gaussian (Gauss MF) were used to model the network (Figure 3). A linear function was applied as output MFs and the combined learning algorithm was used to model the predicted values.

The validation and comparing performance of RBF and ANFIS models were checked out using the comparing parameters such as correlation coefficient ( $r$ ) and the root mean square error (RMSE) as follow.

$$
\begin{aligned}
& R=\left(1-\left(\frac{\sum_{i=1}^{n}\left(z-z^{\prime}\right)^{2}}{\sum_{i=1}^{n} z_{i}^{2}}\right)\right)^{1 / 2} \\
& R M S E=\sqrt{\frac{1}{N} \sum_{i=1}^{N}\left(z-z^{\prime}\right)^{2}}
\end{aligned}
$$

Where $\mathrm{z}$ is the target value and $\mathrm{z}^{\prime}$ is the predicted value by ANFIS network (34)

The root mean square error (RMSE) is applied to measure the differences between predicted values and actually values (target values). Pearson correlation ( $r$ ) is used to measure the linear correlation between two parameters (here are predicted and target variables).

\section{RESULTS AND DISCUSSION Primary results of data}

This section shows the results of experimental treatments on trial data. This result includes different years, different levels of nitrogen application and strategies with a wide range of variation within the investigated crop according to Table 1 . This wide range in the investigated crop variables was investigated in order to make the relationship between plant performance and reflectance values. Based on the Figure1, reflectance in the 
visible region for 2015 increased as compared to 2016, it might be the difference in soil background (15) or this difference can be for higher SPAD value (hence, nitrogen concentrations of leaves and stems) in 2015. As shown in Table 1, an increasing in chlorophyll concentration causes increased reflectance in the visible regions and movement of the red edge to longer wavelengths (4), the position of the red edge in 2015 (around 720) was different from that in other years (around $700 \mathrm{~nm}$ ).

Table 1. Selected property of the investigated crop variables.

\begin{tabular}{|c|c|c|c|c|c|c|}
\hline Crop variables & Year & $\mathbf{n}^{\mathbf{a}}$ & Mean & S.D. & Min & Max \\
\hline \multirow{2}{*}{ SPAD (-) } & 2015 & 56 & 43.1 & 1.38 & 39.4 & 45.3 \\
\hline & 2016 & 40 & 42.6 & 1.62 & 38.2 & 46 \\
\hline \multirow{2}{*}{ Yield (Kg ha $\left.{ }^{-1}\right)$} & 2015 & 56 & 6864 & 966 & 5516 & 8549 \\
\hline & 2016 & 40 & 6708 & 615 & 5450 & 8154 \\
\hline \multirow{2}{*}{ Protein (\%) } & 2015 & 56 & 11.4 & 0.99 & 8.86 & 12.1 \\
\hline & 2016 & 40 & 11.6 & 1.55 & 9.62 & 14.0 \\
\hline
\end{tabular}

As shown in Table. 1, the mean and standard deviation value for SPAD in 2015 is respectively the highest and lowest as compared to 2016, for yield variable 2015 had the highest mean value and standard deviation. While the lowest standard deviation and mean value protein variable was related to 2015. These results can be effected on prediction model performance.

\section{Evaluation of RBF model}

In this study, the RBF method of artificial neural network was developed for modelling a network to predict the growth status of winter wheat based on reflectance measurements. 20 and 25 number of neurons was the optimum number of neurons on hidden layer for 2015 and 2016 data sets, respectively. 70 percent of data was randomly selected as training data and the rest of data selected as testing data by network. The outputs of network was extracted and performance of network was calculated on predicting growth statues on two years for four growth stage (GS36,
GS37, GS45 and GS60) using presented comparing parameters on materials and methods. As an initial result, Figure 4 indicates the results of RBF network on the modelling dataset for two years on GS36, the predicted values of crop variables were plotted against the actual data.The plots show high determination coefficient and high correlation coefficient of predicted values against actual values for 2015 and 2016 datasets. These results represent proximity of predicted and actual values. In order to display the results statistically, the calculated results tabulated on Table. 2 . High R-value and low RMSE value increases the accuracy of network. As shown on Table 2, for each two years from GS36 to GS60, there is a relative decreasing on predicting accuracy and correlation due to decreasing correlation coefficient and increasing RMSE value for SPAD, yield and protein except GS 37 on 2016. 

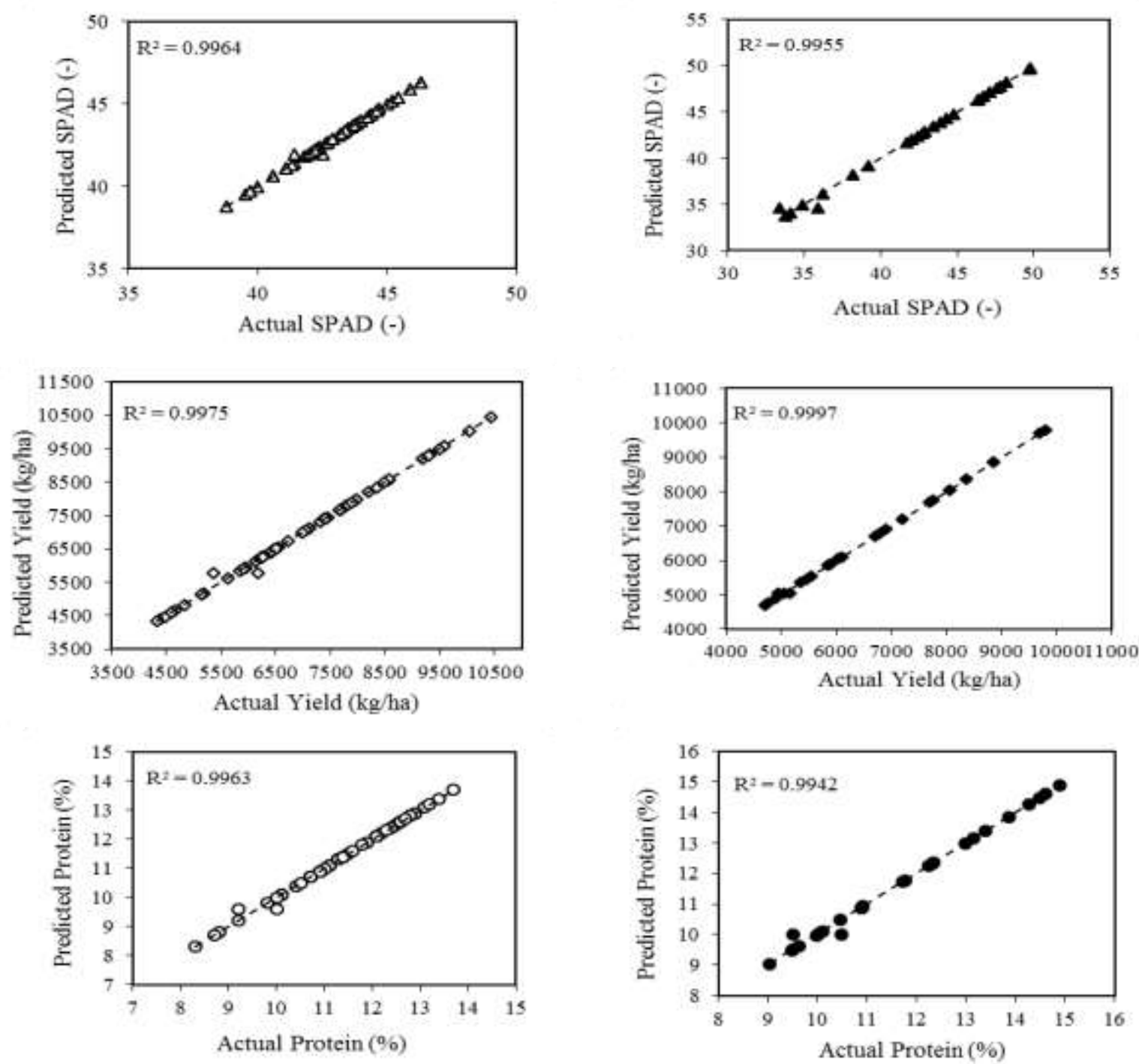

Figure 4. Plots for predicted and actual values of growth status. Left plots indicates 2015 datasets and right plots indicates 2016 datasets.

Based on Table 2, due to proximity of the results of correlation coefficient, the factor of RMSE will be better than correlation coefficient to compare the results. The results show a good relationship between actual crop variables and predicted values for validation datasets. Based on Table. 2, GS36 of 2015 has high correlation coefficient (0.998, 0.998 and 0.998 for SPAD, Yield and Protein, respectively) and low RMSE (0.104, 75.59 and 0.075 for SPAD, Yield and Protein, respectively) compared to other growth stages and on 2016, GS37 has high correlation (0.999 and
0.997) and low RMSE (0.072 and 0.046) for SPAD and Protein, respectively and GS36 with correlation value of 0.999 and RMSE value of 27.22 has the best resubliming the other growth stages. These results of prediction model were obtained without pre-processing operations on data sets.

\section{Evaluating of ANFIS model}

$70 \%$ of the data were used to generate the model, and the remaining (30\%) were used for prediction. The initial ANFIS model was generated by grid partition method. 
Table 2. Performance indices ( $R$ and RMSE) for RBF models.

\begin{tabular}{|lccccccc|}
\hline \multirow{2}{*}{ Year } & & \multicolumn{2}{c}{ SPAD $(-)$} & \multicolumn{2}{c|}{ Yield $(\mathrm{kg} / \mathrm{ha})$} & \multicolumn{2}{c|}{ Protein $(\%)$} \\
\cline { 3 - 8 } & & r & RMSE & r & RMSE & r & RMSE \\
\hline \multirow{4}{*}{2015} & GS36 & $\mathbf{0 . 9 9 8}$ & $\mathbf{0 . 1 0 4}$ & $\mathbf{0 . 9 9 8}$ & $\mathbf{7 5 . 5 9}$ & $\mathbf{0 . 9 9 8}$ & $\mathbf{0 . 0 7 5}$ \\
& GS37 & $\mathbf{0 . 9 8 8}$ & $\mathbf{0 . 1 4 2}$ & $\mathbf{0 . 9 7 7}$ & $\mathbf{1 1 1 . 4 9}$ & $\mathbf{0 . 9 7 5}$ & $\mathbf{0 . 1 2 3}$ \\
& GS45 & $\mathbf{0 . 9 7 8}$ & $\mathbf{0 . 1 7 0}$ & $\mathbf{0 . 9 7 7}$ & $\mathbf{1 1 1 . 5 0}$ & $\mathbf{0 . 9 7 5}$ & $\mathbf{0 . 1 2 3}$ \\
& GS60 & $\mathbf{0 . 9 7 5}$ & $\mathbf{0 . 6 6 9}$ & $\mathbf{0 . 9 7 5}$ & $\mathbf{1 1 4 . 6 8}$ & $\mathbf{0 . 9 7 5}$ & $\mathbf{0 . 1 2 3}$ \\
\hline \multirow{3}{*}{2016} & GS36 & $\mathbf{0 . 9 9 8}$ & $\mathbf{0 . 3 4 0}$ & $\mathbf{0 . 9 9 9}$ & $\mathbf{2 7 . 2 2}$ & $\mathbf{0 . 9 9 7}$ & $\mathbf{0 . 1 3 5}$ \\
& GS37 & $\mathbf{0 . 9 7 9}$ & $\mathbf{0 . 0 7 2}$ & $\mathbf{0 . 9 6 7}$ & $\mathbf{2 4 4 . 1 0}$ & $\mathbf{0 . 9 7 7}$ & $\mathbf{0 . 1 4 6}$ \\
& GS45 & $\mathbf{0 . 9 6 5}$ & $\mathbf{0 . 8 0 9}$ & $\mathbf{0 . 9 7 7}$ & $\mathbf{1 2 3 . 3 9}$ & $\mathbf{0 . 9 7 4}$ & $\mathbf{0 . 1 8 8}$ \\
& GS60 & $\mathbf{0 . 9 7 7}$ & $\mathbf{0 . 4 0 8}$ & $\mathbf{0 . 9 7 9}$ & $\mathbf{2 7 . 2 2}$ & $\mathbf{0 . 9 8 9}$ & $\mathbf{0 . 0 1 6}$ \\
\hline
\end{tabular}
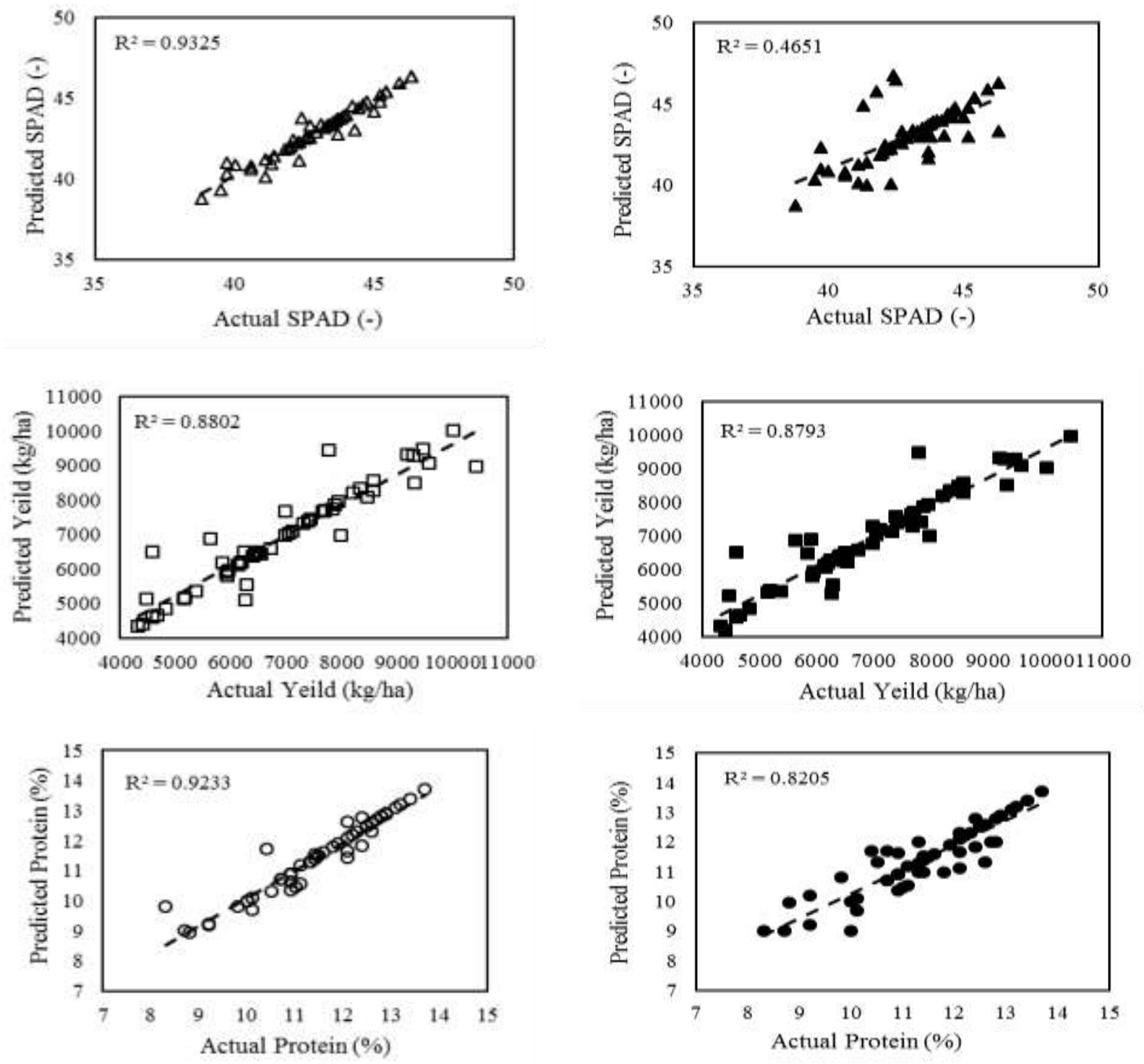

Figure 5. Plots for predicted and actual values of growth status for 2015 datasets. Left plots indicates results of Gaussian MFs and right plots indicates results of Trap MFs.

The fuzzification of input data was performed by two different types of MFs. After training process the ANFIS models were tested using independent data set. The outputs of network was extracted and performance of network was calculated on predicting growth statues on two years for four growth stage (GS36, GS37, GS45 and GS60) using presented comparing parameters on materials and methods. As an initial result, Figure 5 indicates the results of ANFIS on the modelling dataset for two years. 

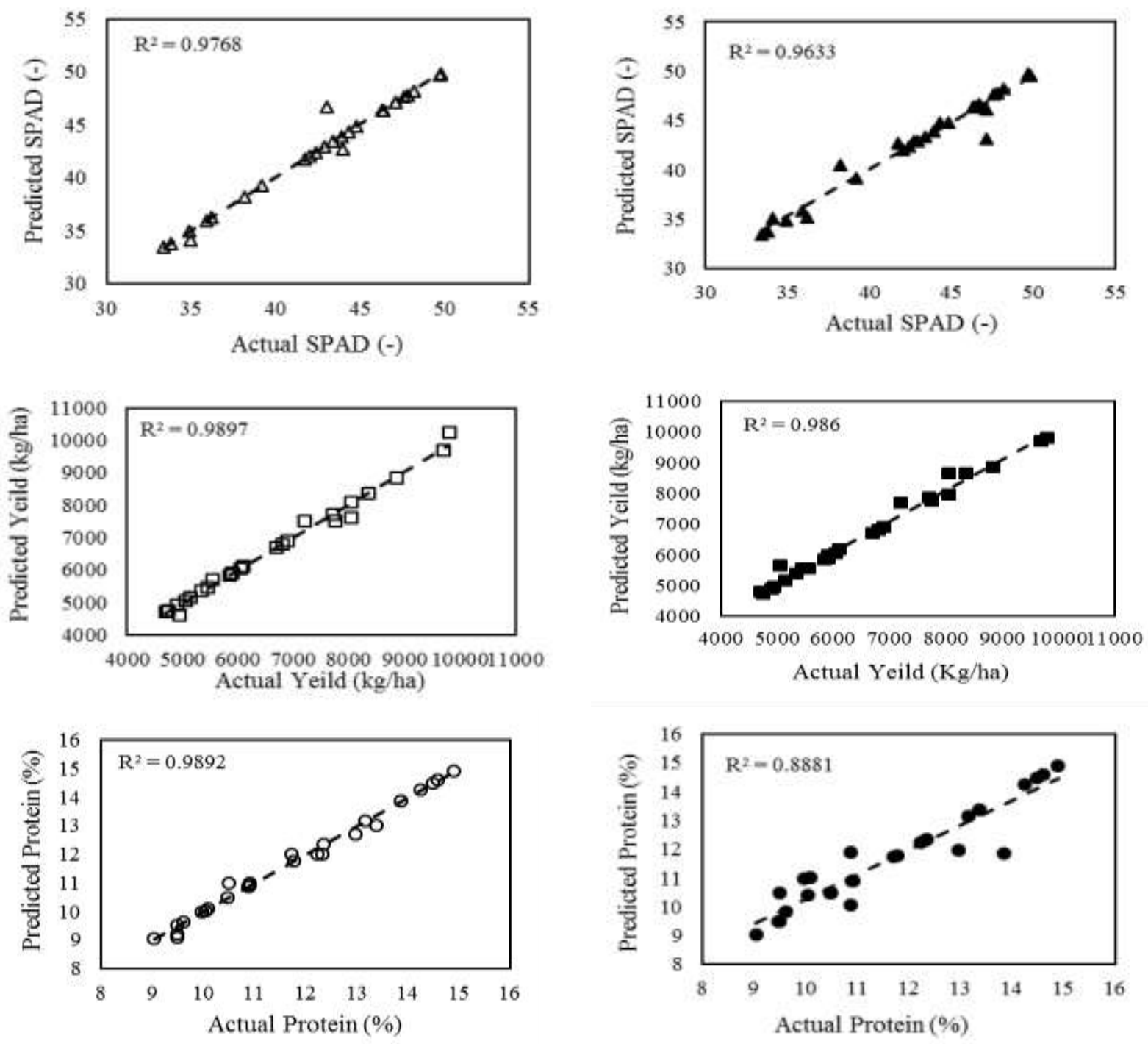

Figure 6. Plots for predicted and actual values of growth status for 2016 datasets. Left plots indicates results of Gaussian MFs and right plots indicates results of Trap MFs.

The relationship between target and predicted values by using two different types of MFs was indicated on Figure 5 and Figure 6 as an initial and schematic result, the predicted values of crop variables were plotted against the actual data.Based on the results of Figure 5 and Figure 6 , the obtained results of Gaussian membership functions have the high correlation and linear relationship compared to the obtained results from trap membership functions which reflects the high ability and high accuracy of Gaussian MFs for learning compared to Trap MFs. Table 3 presents the statically results of ANFIS performance.Based on the results of table 3, Gaussian MFs has the high correlation coefficient and low RMSE values compared to Trap MFs, it means that the output of ANFIS network on Gaussian MFs has the high accuracy and low difference with target values compared to Trap MFs. This claim is true for each two years (2015 and 2016) on each four stages (GS36, GS37, GS45 and GS60) for all dependent variables (SPAD, Yield and Protein). For example, the results of GS36 on 2015 are as follow. For SPAD, yield and protein, Gaussian MFs has high correlation (0.9657, 0.9382 and 0.9609 , respectively) and low difference between output and target values based on the RMSE values (0.4523, 525.685 and 0.3464 , respectively) compared to Trap MFs. 
Table 3. Performance indices (R) and (RMSE) for ANFIS models.

\begin{tabular}{|c|c|c|c|c|c|c|c|c|}
\hline \multirow{2}{*}{ Year } & \multirow{2}{*}{$\begin{array}{c}\text { MF } \\
\text { Type }\end{array}$} & & \multicolumn{2}{|c|}{ SPAD (-) } & \multicolumn{2}{|c|}{ Yield (kg/ha) } & \multicolumn{2}{|c|}{ Protein (\%) } \\
\hline & & & $\mathbf{r}$ & RMSE & $\mathbf{r}$ & RMSE & $\mathbf{r}$ & RMSE \\
\hline \multirow{8}{*}{2015} & Gauss & \multirow{2}{*}{ GS36 } & 0.9657 & 0.4523 & 0.9382 & 525.685 & 0.9609 & 0.3464 \\
\hline & Trap & & 0.6819 & 1.0887 & 0.8977 & 588.1 & 0.9058 & 0.5300 \\
\hline & Gauss & \multirow{2}{*}{ GS37 } & 0.9287 & 0.832 & 0.9473 & 486.58 & 0.9730 & 0.2887 \\
\hline & Trap & & 0.7929 & 1.5669 & 0.9258 & 580.715 & 0.9053 & 0.5480 \\
\hline & Gauss & \multirow{2}{*}{ GS45 } & 0.98 & 0.091 & 0.9998 & 300.28 & 0.989 & 0.0213 \\
\hline & Trap & & 0.9079 & 1.4751 & 0.9891 & 229.362 & 0.6086 & 1.3707 \\
\hline & Gauss & \multirow{2}{*}{ GS60 } & 0.9952 & 0.652 & 0.9998 & 260.81 & 0.998 & 0.0099 \\
\hline & Trap & & 0.982 & 1.2762 & 0.9927 & 183.775 & 0.9252 & 0.5007 \\
\hline \multirow{8}{*}{2016} & Gauss & \multirow{2}{*}{ GS36 } & 0.988 & 0.0021 & 0.995 & 49.5 & 0.98 & 0.0094 \\
\hline & Trap & & 0.9815 & 0.0750 & 0.9930 & 204.836 & 0.9424 & 0.5969 \\
\hline & Gauss & \multirow{2}{*}{ GS37 } & 0.9426 & 0.144 & 0.985 & 140.646 & 0.976 & 0.0137 \\
\hline & Trap & & 0.9276 & 1.7632 & 0.9788 & 180.644 & 0.9653 & 0.4734 \\
\hline & Gauss & \multirow{2}{*}{ GS45 } & 0.969 & 1.2126 & 0.9705 & 375.555 & 0.9798 & 0.3578 \\
\hline & Trap & & 0.9002 & 2.1393 & 0.9580 & 388.765 & 0.9438 & 0.5923 \\
\hline & Gauss & \multirow{2}{*}{ GS60 } & 0.9851 & 0.9926 & 0.9898 & 222.608 & 0.9909 & 0.2643 \\
\hline & Trap & & 0.9626 & 1.5212 & 0.9888 & 231.908 & 0.9199 & 0.6996 \\
\hline
\end{tabular}

This result is also true for the rest of the results of Figure 4, Figure 5 and Figure 6, it year and growth stages, without exception, but in some cases has high intensity (GS36 on 2015) and in some cases has low intensity (GS60 on 2015 and 2016). Therefore, due to the best results of Gaussian MFs compared to Trap MFs, it was chosen as the best type of membership function and the network was trained with Gaussian function.

\section{Comparing ANFIS and RBF models}

In order to compare the results of two networks we need statics and attributable information. Figure 4 and Figure 5 take a graphically, initial and simple result of can be taken that the linear relationship of RBF results is stranger than ANFIS results due to its high values of determination coefficient and correlation coefficient and also about ANFIS results, Gaussian MFs showed high linear relationship between target and output values compared to Trap MFs. To prove this claim, the static results extracted and tabulated on Table 4 Because of the extent of output and the impossibility of comparing parameters one by one, these results tabulated in terms of the average value of comparative parameters for each network separately on table 4 . comparing two methods. Based on the

Table 4. Average amount of performance indices ( $R$ and RMSE) for predictor models.

\begin{tabular}{|cccccccccc|}
\hline \multirow{2}{*}{ Year } & \multirow{2}{*}{ Net } & & \multicolumn{2}{c}{ SPAD } & \multicolumn{2}{c}{ Yield } & \multicolumn{2}{c|}{ Protein } \\
\cline { 3 - 9 } & & & r & RMSE & r & RMSE & r & RMSE \\
\hline \multirow{2}{*}{2015} & \multirow{2}{*}{ ANFIS } & Gaus & S & $\mathbf{0 . 9 6 7}$ & $\mathbf{0 . 5 0 7}$ & $\mathbf{0 . 9 7 1}$ & 393.338 & 0.98 & 0.166 \\
& & Trap & $\mathbf{0 . 8 4 1}$ & $\mathbf{1 . 3 5 2}$ & $\mathbf{0 . 9 5 1}$ & $\mathbf{3 9 5 . 4 8 8}$ & $\mathbf{0 . 8 3 6}$ & $\mathbf{0 . 7 3 7}$ \\
& RBF & - & $\mathbf{0 . 9 8 4}$ & $\mathbf{0 . 2 7 1}$ & $\mathbf{0 . 9 8 1}$ & $\mathbf{1 0 3 . 3 1 5}$ & $\mathbf{0 . 9 8 0 7}$ & $\mathbf{0 . 1 1 1}$ \\
\hline \multirow{2}{*}{2016} & \multirow{2}{*}{ ANFIS } & Gaus & $\mathbf{0 . 9 7 1}$ & $\mathbf{0 . 5 8 7}$ & $\mathbf{0 . 9 8}$ & $\mathbf{1 9 7 . 0 7 6}$ & $\mathbf{0 . 9 8 1}$ & $\mathbf{0 . 1 6 1}$ \\
& & Trap & $\mathbf{0 . 9 4 3}$ & $\mathbf{1 . 3 7 4}$ & $\mathbf{0 . 9 7 9}$ & $\mathbf{2 5 1 . 5 3 8}$ & $\mathbf{0 . 9 4 3}$ & $\mathbf{0 . 5 9 1}$ \\
& RBF & - & $\mathbf{0 . 9 7 9}$ & $\mathbf{0 . 4 0 7}$ & $\mathbf{0 . 9 8 0 5}$ & $\mathbf{1 0 5 . 4 8 2}$ & $\mathbf{0 . 9 8 4}$ & $\mathbf{0 . 1 2 1}$ \\
\hline
\end{tabular}


As shown on Table 4, RBF network with high correlation coefficient $(0.984,0.981$ and 0.9807 in 2015 for SPAD, yield and protein, respectively and $0.979,0.9805$ and 0.984 in 2016) and low RMSE (0.271, 103.315 and 0.111 in 2015 for SPAD, yield and protein, respectively and $0.407,105.482$ and 0.121 in 2016) shows high accuracy, high linear relationship and high performance, compared to ANFIS. Between two types of membership functions of ANFIS model developing, based on Table 4, Gaussian MFs with high correlation coefficient $(0.967,0.971$ and 0.98 in 2015 for SPAD, yield and protein, respectively and $0.971,0.98$ and 0.981 in 2016) and low RMSE (0.507, 393.388 and 0.166 in 2015 for SPAD, yield and protein, respectively and $0.587,197.076$ and 0.161 in 2016) has high performance an high accuracy compared to Trap MFs. On the other hand, based on the results of Table 3, due to the gap in the numbers of Table 3 for ANFIS output, the results show significant instability in the provision and unlike ANFIS, RBF in addition to high performance (Table 4) shows instability in presenting the results (Table 2). According to the results, the final decision is to select and to recommend the RBF method among three learning methods (RBF, ANFIS with gauss MFs and ANFIS with Trap MFs) as the best and precise predictor method of SPAD, Yield and protein using wavelength as the only independent input of network. Rasooli sharabian et al. (25) on a study about determining the important wavelength using multivariate analysis including of PLSR and SMLR procedures for prediction of grain yield and winter wheat growth status, reported strong relationships between predicted and actual crop variables (Sharabian et al., 2014). The best prediction model selected by SMLR on maximum data normalization for $\mathrm{R}^{2}$ and RMSR were 0.84, 1.94 for SPAD, 0.87, 301 for grain yield, and $0.80,0.786$ for protein content. On a study by Gupta et al. (10). Evaluation of rice crop growth situation was performed using two types of feed forward back propagation neural network (FFBPANN) models namely FFBPANN-I and FFBPANNII model. The FFBPANN-I model was expanded using a input neuron $(\mathrm{VV}$ - or $\mathrm{HH}$ - polarized scattering coefficient) and a output neuron (leaf area or biomass index, chlorophyll content or plant height), while the FFBPANN-II model was expanded using two input neurons (VV and $\mathrm{HH}$ polarized scattering coefficient) and four output neurons (leaf area index, biomass, chlorophyll content and plant height). Results indicated a good estimating performance for $\mathrm{HH}-$ and $\mathrm{VV}$ polarized scattering. In general, $\mathrm{R}^{2}$ and RMS error between observed and FFBPANN predicted values of crop parameters was reported as 0.993 and 0.118 for $\mathrm{HH}-$ Polarization, 0.982 and 0.157 for VVpolarization and 0997 and 0.057 for combination of $\mathrm{HH}$ and VV polarizations. On a other study by Liu et al. (18) a back propagation (BP) neural-network model was applied to predict the concentration of rice chlorophyll under heavy stress of metal on three experiment farms placed in Changchun, Jilin Province, China with level II pollution, I pollution and with safe level. The value of $\mathrm{R}^{2}$ and RMSE for prediction of chlorophyll concentration was obtained 0.9014 and 2.58, respectively. The obtained results of present study is following the previous researches. The positive point of this study is to use different methods (RBF and ANFIS) for predicting growth status of winter wheat. Based on the results of the other predicting methods that was conducted in predicting winter wheat status, it can be said the present methods have high ability in prediction of variables. This is due to the nature of soft computing techniques. Important wavelengths were obtained using regression analysis on SPSS software using the output values of the best predictor (RBF network). Some wavelengths $[(580,660,665$, 720, 740, 800, 930, 990, 1010, 1110, 1120, $1150,1240$ and $1340 \mathrm{~nm}),(580,660,720,740$, 800, 930, 990, 1010,1110,1120,1150, 1240 and $1340 \mathrm{~nm})$ and $(580,660,720,740,800$, 930, 990 and 1010)] were identified by RBF as significant wavelengths for SPAD, grain yield and protein content, respectively for 2016 and $[(590,640,680,690,710,730,750,770,780$, $940,1000,1010,1070,1170,1130,1290$ and 1350), ( 590, 640, 680, 690, 710, 730, 750, 770, 780, 940, 1000, 1010, 1070, 1130, 1170, 1290 and 1350) and (590, 640, 680, 690, 710, 
730, 750, 770, 1010, 1070, 1170, 1290 and 1350)] were identified for the value of SPAD, grain yield and protein, respectively for 2015.The goal of this study was to model the SPAD, yield and protein of plant using wavelength using soft computing methods. ANFIS and RBF were selected as the predictor of system and were trained and tested. Results indicated that the obtained results of $\mathrm{RBF}$ method with high average correlation coefficient $(0.984,0.981$ and 0.9807 in 2015 for SPAD, yield and protein, respectively and $0.979,0.9805$ and 0.984 in 2016) and low RMSE (0.271, 103.315 and 0.111 in 2015 for SPAD, yield and protein, respectively and $0.407,105.482$ and 0.121 in 2016) has the high accuracy and high performance compared to ANFIS models, then it was selected as the best predictor. Eventually, RBF network was proposed as the estimator network for studied outputs based on related input and was used to obtain the important wavelength.

\section{Conflict of interest}

There is no conflict of interest.

\section{REFERENCES}

1.Abbasi, A., and R. Eslamloueyan.2014. Determination of binary diffusion coefficients of hydrocarbon mixtures using MLP and ANFIS networks based on QSPR method. Chemometrics and Intelligent Laboratory Systems, 132, 39-51. doi: 10.1016/ j.chemolab.2013.12.007

2.Card, D. H.,D.L. Peterson, P.A. Matson and J.D. Aber . 1988. Prediction of leaf chemistry by the use of visible and near infrared reflectance spectroscopy. Remote Sensing of Environment, 26(2), 123-147.

3.Chang, J.-R., L.Y.,Wei, and C.H. Cheng, . 2011. A hybrid ANFIS model based on AR and volatility for TAIEX forecasting. Applied Soft Computing, 11(1), 1388-1395.

4.Demetriades-Shah, T. H., M.D. Steven, and J.A., Clark .1990. High resolution derivative spectra in remote sensing. Remote Sensing of Environment, 33(1), 55-64.

5.Du, D.,K. Li, and M. Fei. 2010. A fast multioutput RBF neural network construction method. Neurocomputing, 73(10), 2196-2202.

6.Faizollahzadeh Ardabili, S., A. Mahmoudi, and T. Mesri Gundoshmian. 2016. Modeling and simulation controlling system of HVAC using fuzzy and predictive (radial basis function ,RBF) controllers. Journal of Building Engineering, 6, 301-308.

7.Fathi, V., and G.A. Montazer. 2013. An improvement in RBF learning algorithm based on PSO for real time applications. Neurocomputing, 111, 169-176.

8.Foody, G., 2004. Supervised image classification by MLP and RBF neural networks with and without an exhaustively defined set of classes. International Journal of Remote Sensing, 25(15), 3091-3104.

9.Ghiasi, M. M., M. Arabloo, A.H. Mohammadi, and T. Barghi .2016. Application of ANFIS soft computing technique in modeling the $\mathrm{CO} 2$ capture with MEA, DEA, and TEA aqueous solutions. International Journal of Greenhouse Gas Control, 49, 47-54. doi: 10.1016/ j.ijggc. 2016.02.015

10.Gupta, D., P. Kumar, V.Mishra, R. Prasad, P. Dikshit, S. Dwivedi, , and V. Srivastava .2015. Bistatic measurements for the estimation of rice crop variables using artificial neural network. Advances in Space Research, 55(6), 1613-1623.

11.Hansen, P.,J.R., Jørgensen and A. Thomsen, . 2002. Predicting grain yield and protein content in winter wheat and spring barley using repeated canopy reflectance measurements and partial least squares regression. The Journal of Agricultural Science, 139(03), 307-318.

12.İnal, M., 2008. Determination of dielectric properties of insulator materials by means of ANFIS: a comparative study. journal of materials processing technology, 195(1), 34-43.

13.Kahriman, F., K. Demirel, M. Inalpulat, C.O.Egesel and L. Genc . 2016. Using leaf based hyperspectral models for monitoring biochemical constituents and plant phenotyping in maize. $\mathrm{J}$. Agr. Sci. Tech., Vol. 18, 1705-1718.

14.Kalubarme, M.,M. Potdar, R. Manjunath, K., Mahey and S. Siddhu. 2003. Growth profile based crop yield models: a case study of large area wheat yield modelling and its extendibility using atmospheric corrected NOAA AVHRR data. International Journal of Remote Sensing, 24(10), 2037-2054.

15.Kimura, R., S. Okada, H. Miura, H. and M. Kamichika . 2004. Relationships among the leaf area index, moisture availability, and spectral reflectance in an upland rice field. Agricultural Water Management, 69(2), 83-100.

16.Labbafi, M., H.Khalaj, I. Allahdadi, F. Nadjafi and G.A. Akbari. 2019. Using models for estimation of leaf area index in Cucurbita pepo L. Journal of the Saudi Society of Agricultural Sciences, 18(1), 55-60. doi: 10.1016/ j.jssas. 2016.12.006 
17.Lee, K., D. Lee, K. Sudduth, S. Chung , N. Kitchen, and S. Drummond. 2009. Wavelength identification and diffuse reflectance estimation for surface and profile soil properties. Trans. ASABE, 52(3), 683-695.

18.Liu, M., X. Liu, M. Li, M. Fang and W. Chi, 2010. Neural-network model for estimating leaf chlorophyll concentration in rice under stress from heavy metals using four spectral indices. Biosystems engineering, 106(3), 223-233.

19.Mkhabela, M. S., M.S. Mkhabela, and N.N. Mashinini. 2005. Early maize yield forecasting in the four agro-ecological regions of Swaziland using NDVI data derived from NOAA's-AVHRR. Agricultural and Forest Meteorology, 129(1), 1-9. 20.Naderloo, L., R.Alimardani, M. Omid, F. Sarmadian, P. Javadikia, M.Y. Torabi and F. Alimardani. 2012. Application of ANFIS to predict crop yield based on different energy inputs. Measurement, 45(6), 1406-1413.

21.Patrício, D. I., and R. Rieder. 2018. Computer vision and artificial intelligence in precision agriculture for grain crops: A systematic review. Computers and Electronics in Agriculture, 153, 6981. doi:10.1016/j.compag.2018.08.001

22.Peñuelas, J.and I. Filella, . 1998. Visible and near-infrared reflectance techniques for diagnosing plant physiological status. Trends In Plant Science, 3(4), 151-156.

23.Polat, K., and S. Güneş . 2007. Automatic determination of diseases related to lymph system from lymphography data using principles component analysis (PCA), fuzzy weighting preprocessing and ANFIS. Expert Systems with Applications, 33(3), 636-641.

24.Rasooli Sharabian, V., 2013. Development of a Real-time Optical Sensor for Detecting Wheat Growth Status.

25.Rasooli Sharabian, V., N.Noguchi, I. Han-Ya, and K. Ishi, .2013. Evaluation of an active remote sensor for monitoring winter wheat growth status. Engineering in Agriculture, Environment and Food, 6(3), 118-127.

26.Royo, C., N. Aparicio, D. Villegas, J. Casadesus, P. Monneveux, and J. Araus, . 2003. Usefulness of spectral reflectance indices as durum wheat yield predictors under contrasting
Mediterranean conditions. International Journal of Remote Sensing, 24(22), 4403-4419.

27.Sharabian, V. R., N. Noguchi and K. Ishi . 2014. Significant wavelengths for prediction of winter wheat growth status and grain yield using multivariate analysis. Engineering in Agriculture, Environment and Food, 7(1), 14-21.

28.Soyguder, S., and H. Alli, . 2009. An expert system for the humidity and temperature control in HVAC systems using ANFIS and optimization with Fuzzy Modeling Approach. Energy and Buildings, 41(8), 814-822. doi:10.1016/j.enbuild.2009.03.003

29.Stroppiana, D. , P. Villa, G. Sona, G. Ronchetti, G. Candiani, M. Pepe, and M. Boschetti, .2018. Early season weed mapping in rice crops using multi-spectral UAV data. International Journal of Remote Sensing, 39(15-16), 5432-5452. doi:10.1080/01431161.2018.1441569

30.Tumbo, S., D. Wagner, and P. Heinemann . 2002. Hyperspectral-based neural network for predicting chlorophyll status in corn. Transactions of the ASAE, 45(3), 825-832.

31.Wood, G. A., J. C. Taylor and R.J. Godwin, . 2003. Calibration methodology for mapping within-field crop variability using remote sensing. Biosystems engineering, 84(4), 409-423.

32.Xianhai, G., 2011. Study of Emotion Recognition Based on Electrocardiogram and RBF neural network. Procedia Engineering, 15, 24082412.

33.Yilmaz, I., and O. Kaynar . 2011. Multiple regression, ANN (RBF, MLP) and ANFIS models for prediction of swell potential of clayey soils. Expert Systems with Applications, 38(5), 59585966.

34.Yilmaz, I., and G. Yuksek . 2009. Prediction of the strength and elasticity modulus of gypsum using multiple regression, ANN, and ANFIS models. International Journal of Rock Mechanics and Mining Sciences, 46(4), 803-810.

35.Zhang, J., K. Wang and R. Wang, .2003. Application of chlorophyll meter SPAD-502 in diagnosis of nitrogen status and nitrogenous fertilizer in rice. Journal of Northwest A\&F University (Natural Science Edition), 31(2), 177180 . 